\title{
Effect of Machining Parameters in Electrical Discharge Machining of D2 Tool Steel
}

\author{
Raman K ${ }^{1}$, Sathiya G $K^{2}$, Saisujith $K^{3}$, Mani $P^{4}$ \\ ${ }^{1,2,3,4}$ Assistant Professor, Department of Mechanical Engineering, GRT Institute of Engineering and Technology, Tiruttani-631209
}

\begin{abstract}
Electrical discharge machining (EDM) is one of the important non-traditional machining processes and it is widely accepted as a standard machining process in the manufacture of forming tools to produce molds and dies. Since its introduction to manufacturing industry in late 1940s, EDM became a well-known machining method. The method is based on removing material from a work piece by means of a series of repeated electrical discharges, produced by electric pulse generators at short intervals, between an electrode (tool) and a part being machined in dielectric fluid medium. Copper electrodes with diameter of 9.5, 12 and 20 mm were used in electrode discharge machining of AISI D2 tool steel at two current setting of 3.5 and $6.5 \mathrm{~A}$ with the objective of determining possible correlation between the EDM parameter and the machinability factors. Each machining test was performed for 20 min and kerosene was used as the dielectric fluid. The material removal rate of the work piece material and wear rate of the electrode material were obtained based on the calculation of the percentage of mass loss per machining time. It was found that the material removal rate as well as the electrode wear rate was not only dependent on the diameter of the electrode, but also had close relation with the supply of current. Low current was found suitable for small diameter electrode, while high current for big diameter electrode.
\end{abstract}

Keywords: EDM; Material removal rate, Electrode wear rate

\section{Introduction}

From the machining technique point of view, electrode discharge machining is classified as a non traditional machining technique. This technique has been widely used in modern metal working industry and its versatility and ability to cut fully hardened steels has enabled it to be widely accepted, especially in the die making industry in addition to high speed machining applications.

The basic process in EDM is carried out by producing controlled electric sparks between a tool and the work piece, both of which are immersed in a dielectric fluid. The electric spark raises the surface temperature of both the electrode and work piece to a point where the surface temperatures are in excess of the melting are even boiling points of the substances[1].

Metal is thus primarily removed in the liquid and vapour phases. By the controlling the electrical parameters, removal of material may be confined to some extent to the work piece. Wear of the tool, however, cannot be ignored because when this occurs the geometrical characteristics of the electrode will not be reproduced on the work piece. The surface generated by EDM consists of debris, which has been melted on vaporized during machining, lying on or in corrupted into the cratered spark eroded surface. This resulting product of the erosion process, commonly known as debris, has an important relation to the various aspects of EDM [2]. Debris formation is analog to chip formation in traditional machining, and normally debris has a spherical shape with slight ellipticity. Usually, the size as well as the formation of debris depends on the current supplied during machining [3].

With the above in mind, studies were conducted on EDM of
AISI D2 tool steel using copper electrodes to determine possible correlation between the EDM parameter and the machinability of the work piece material. The machinability factors investigated were limited to the material removal rate and the electrode wear rate.

\section{Experimental Details}

A) Work piece and electrode material

In this paper, AISI D2 tool steel was selected as the work piece material. The material was supplied in fully annealed condition and was cut to $100 \mathrm{~mm} \times 100 \mathrm{~mm} \times 40 \mathrm{~mm}$ in size.

\begin{tabular}{|c|c|}
\hline Element & $\mathrm{Wt} \%$ \\
\hline $\mathrm{C}$ & 1.5 \\
\hline $\mathrm{Si}$ & 0.3 \\
\hline $\mathrm{Mn}$ & 0.3 \\
\hline $\mathrm{Mo}$ & 1 \\
\hline $\mathrm{G}$ & 12 \\
\hline $\mathrm{Ni}$ & 0.3 \\
\hline $\mathrm{V}$ & 0.8 \\
\hline $\mathrm{Co}$ & 1 \\
\hline $\mathrm{Fe}$ & balance \\
\hline
\end{tabular}

B) Experimental Techniques

The work piece and the electrode were mounted on an EDM machine and kerosene was used as the dielectric fluid. Machining tests were carried out at two current settings ( 3.5 and $6.5 \mathrm{~A}$ ) with the total machining time of $20 \mathrm{~min}$ for each size of electrode. In this study two assumptions were made: (a) temperature and pressure of dielectric fluid were assumed to be constant; (b) current consumption were constant throughout the experiments.

In order to obtain the data to show the relation between the machining parameter and the machinability factors when

Volume 6 Issue 7, July 2017 


\section{International Journal of Science and Research (IJSR) \\ ISSN (Online): 2319-7064 \\ Index Copernicus Value (2015): 78.96 | Impact Factor (2015): 6.391}

machining using EDM, a certain machining features, namely a blind hole, was selected to be machined. A number of machined holes were machined where the diameter of the holes was the same as the diameter of the electrode used.

Material removal rate of the work piece material and the wear rate of the electrode were obtained based on the calculation of the percentage of mass loss per machining time. The observations and measurements to determine the material removal rate and the wear rate were recorded every 4 min throughout the EDM experiments.

\section{Results and Discussion}

\section{A) Material removal rate}

The percentages of mass loss of work piece material when machining at two current settings of 3.5 and $6.5 \mathrm{~A}$ using electrodes with diameter of $9.5,12$ and $20 \mathrm{~mm}$ are shown in Figures 1 and 2, respectively. Although different in magnitude, the percentage of mass loss at higher current $(6.5$ A) setting is greater than at lower current (3.5 A) setting, and the trend of the curves are similar in nature.

The initial mass loss for the first 4 min of machining is almost the same for electrodes. In Fig.1, at current setting of $3.5 \mathrm{~A}$, the initial value is $0.05-0.08$ wt.\%, while in Fig. 2, at current setting of $6.5 \mathrm{~A}$, it is $0.53-0.73 \mathrm{wt} . \%$.

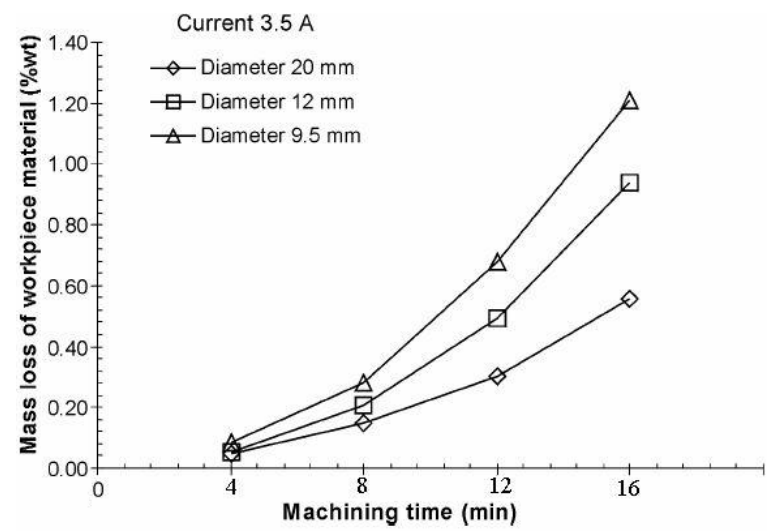

Figure 2: Percentage of mass loss of workpiece material at a current settings of $3.5 \mathrm{~A}$.

From Fig.2, it is observed that the electrode with the diameter results in a higher percentage of mass loss of work piece material than the electrode with the smaller diameter. In contrast, the results in Fig.1 show that the electrode with the smaller diameter the performs better than the bigger diameter electrodes. It seems that the electrode diameter of $20 \mathrm{~mm}$ is ineffective when used at a current setting of $3.5 \mathrm{~A}$, but performs better when the current setting is at $6.5 \mathrm{~A}$. Based on this evidence, it can be concluded that the material removal rate is not only depend on the diameter of electrode, but also has close relation with the supply of current. Additionally, low current is found suitable fore small diameter electrode whilst the high current for big diameter electrode.

Theoretically, when current is assumed to be constant throughout the EDM tests, the mass loss per machining time is supposed to be line. However, from the curves obtained in fig.1and 2, concave behavior of curves is observed to represent the relation between the percentages of mass loss to machining time. This result probably occurs due to a number of reasons. First of all, there is loss of thermal energy to the atmosphere and to the dielectric fluid. Although the dielectric fluid is assumed to be at constant temperature and pressure, thermal energy is, however, absorbed by the dielectric fluid due to the high temperature generated during machining. The surface temperature in EDM is relatively high, almost equal to the point of the work piece material. Secondly, there is also the problem of debris formation and ejection when milling a blind hole using a vertical milling machine under wet or dry cutting condition where chips are gathered inside the hole; in EDM, debris remains inside the hole and reduces the machining performance. Thirdly, the contact surface as well as on the electrode surface. Moreover, the worn electrode also reduces the

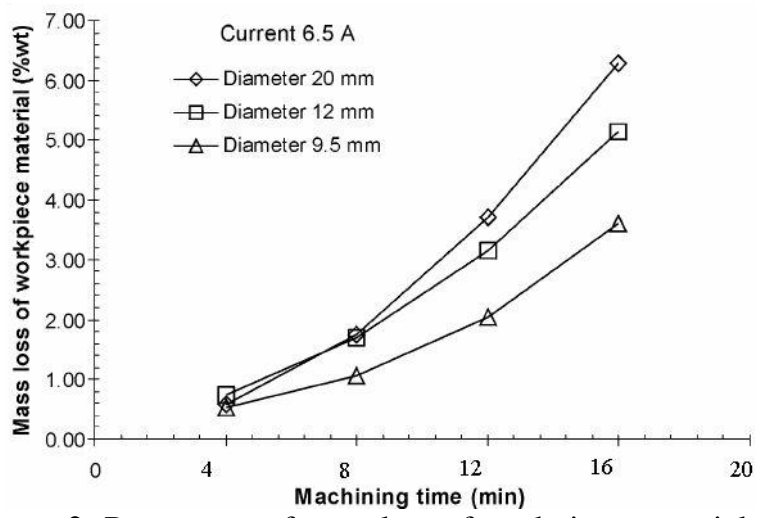

Figure 2: Percentage of mass loss of workpiece material at a current settings of $6.5 \mathrm{~A}$.

contact surface. Finally, there is the classical machining problem. Tool vibration. In particular, when rotary EDM is employed, the electrode rotates like a tool in a milling operation and vibration may occur and this reduces the material removal rate.

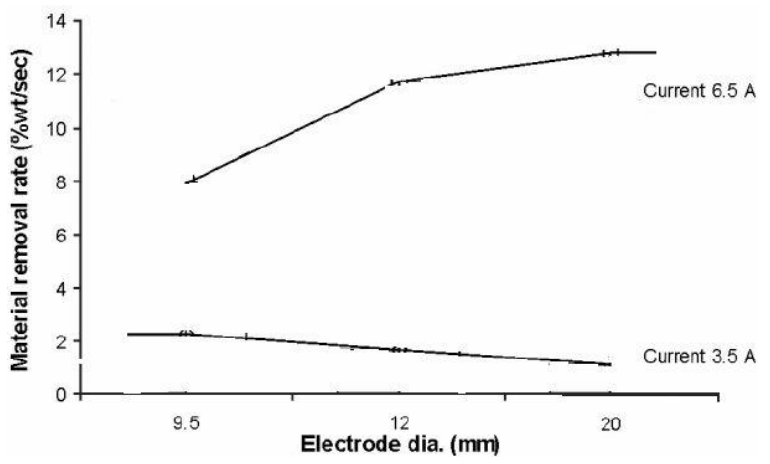

Figure 3: Material removal rate of workpiece material at two current settings of 3.5 and $6.5 \mathrm{~A}$.

Figure 3 shows the material removal rate of the work piece material at two current settings. It can be seen that the performance at high current setting is better than that at lower current setting in terms of the material removal rate. In the case of current setting at $3.5 \mathrm{~A}$, the material removal rate 


\section{International Journal of Science and Research (IJSR) \\ ISSN (Online): 2319-7064 \\ Index Copernicus Value (2015): 78.96 | Impact Factor (2015): 6.391}

decreases linearly from small electrode diameter $(9.5 \mathrm{~mm})$ to higher electrode diameter (12 and $20 \mathrm{~mm}$ ). For current setting of $6.5 \mathrm{~A}$, the material removal rate increase in a convex fashion from smaller electrode diameter $(9.5 \mathrm{~mm})$ to higher electrode diameter (12 and $20 \mathrm{~mm}$ ).

B) Electrode Wear Rate

The percentages of mass loss of electrodes with diameter 9.5, 12and $20 \mathrm{~mm}$ when machining at two current settings of 3.5 and 6.5 A are shown in figs. 4 and 5, respectively. From these figures, the curves can be said to have the following characteristics; (a) linear characteristic, which agrees with the theory of constant current, mostly found in fig.4; (b) concave curves, which are similar to the characteristics of the material removal curves, found in fig.5.

The initial value of electrode wear for the first $4 \mathrm{~min}$ is almost the same for all electrodes and this is similar to the results of material removal rate of the work piece as shown figs. 1 and 2 . The exception is found only on electrode with diameter 9.5 $\mathrm{mm}$ at current setting of $3.5 \mathrm{~A}$ (Fig.4). However this result is the most ideal, where the curve is perfectly linear.

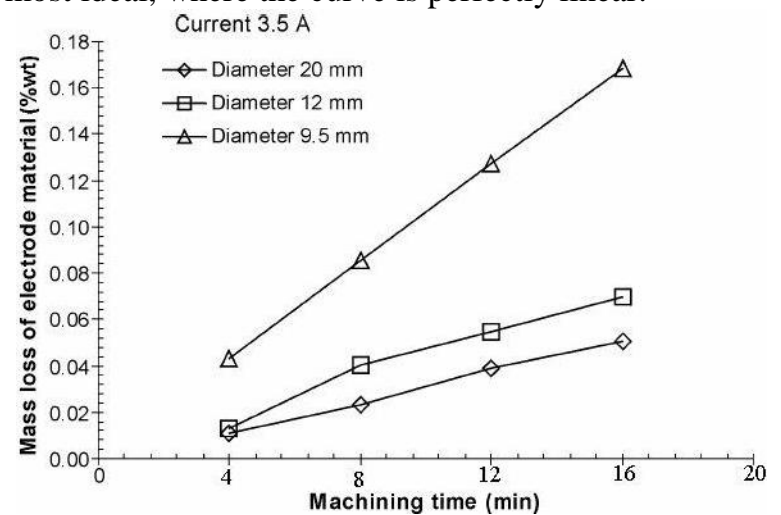

Figure 4: Percentage of mass loss of electrode material at current settings of $3.5 \mathrm{~A}$.

From the curves plotted in fig.4, it was observed that the electrode with smaller diameter $(9.5 \mathrm{~mm})$ had a higher percentage of mass loss than the electrode with bigger diameter, such as 12 and $20 \mathrm{~mm}$. it is expected that this characteristics also applies to the results in fig. 5 when $6.5 \mathrm{~A}$ of current is supplied. This expectation is supported by the fact that the initial value of wear or mass loss of electrode with 9.5 $\mathrm{mm}$ diameter is higher than the initial wear value of electrode with $12 \mathrm{~mm}$ diameter (fig.5).

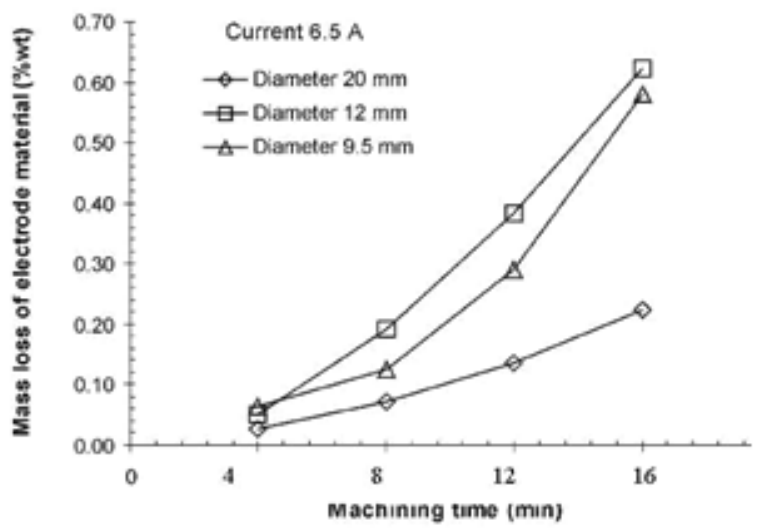

Figure 5: Percentage of mass loss of electrode material at current settings of $6.5 \mathrm{~A}$.

However, the curves in fig. 5 show that the mass loss of the electrode with $12 \mathrm{~mm}$ diameter is

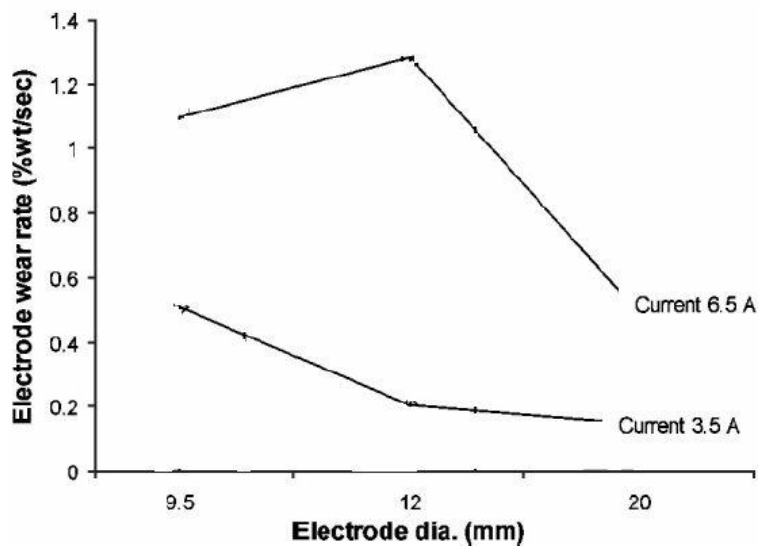

Figure 6: Material removal rate of electrode material at two various current settings of 3.5 and $6.5 \mathrm{~A}$

higher than the electrode with $9.5 \mathrm{~mm}$ diameter, while the electrode with $20 \mathrm{~mm}$ diameter still satisfies the expectation. The occurrences of the unexpected results may be due to two main reasons that is thermal loss during machining and the melting point of electrode material. When the electrode with $12 \mathrm{~mm}$ diameter was used, thermal energy lost to the atmosphere and the dielectric liquid was more than that using electrode with $9.5 \mathrm{~mm}$ diameter. Thus, the temperature was not constant when approaching the melting point of electrode material. As a result, wear or loss on the electrode with $12 \mathrm{~mm}$ diameter is less than the wear or mass loss on the electrode with $9.5 \mathrm{~mm}$ diameter.

Further description of the wear rate of electrode at the two current setting is presented in fig.6. in the case of current setting at $3.5 \mathrm{~A}$, the wear rate decreases in a concave manner from the smaller electrode diameter $(9.5 \mathrm{~mm})$ to the higher electrode diameter (12 and 20mm) . For a current setting of $6.5 \mathrm{~A}$, higher wear rate is on the electrode diameter of $12 \mathrm{~mm}$, followed by 9.5 and $20 \mathrm{~mm}$.

From the discussion of the material removal rate and wear rate, it can be concluded that the best performance is given by 


\section{International Journal of Science and Research (IJSR) \\ ISSN (Online): 2319-7064 \\ Index Copernicus Value (2015): 78.96 | Impact Factor (2015): 6.391}

the electrode diameter of $20 \mathrm{~mm}$ with a current setting of $6.5 \mathrm{~A}$, since this combination gives the highest material removal rate (fig.3) the lowest wear rate (fig.6).

\section{Conclusion}

The following conclusion is drawn to describe the relation of the machining parameter and the machinability factor when machining tool steel using EDM.

Based on the material removal rate of the work piece and the wear rate of the electrode, it can be concluded that the best performance was given by electrode with the diameter of $20 \mathrm{~mm}$ at a current setting $6.5 \mathrm{~A}$, scince this combination gives the highest material removal rate and the lowest wear rate. The curves representing the percentages of mass loss work piece material when machining at two current setting of 3.5 and 6.5 A using copper electrode with diameter of $9.5,12$ and $20 \mathrm{~mm}$ are different magnitude, but similar in trend.

The initial value of mass loss, both for work piece material and electrode material, for the first four minutes of machining was almost same for all electrodes used in this study. The material removal rate and the electrode wear rate were not only dependent on diameter of electrode, but also had close relation with the supply of current. Low current was found suitable for small diameter electrode, and high current for big diameter electrode. In the case of current setting at 3.5 A, the material removal rate decreases linearly from the smaller electrode diameter to the higher electrode diameter .For current setting of $6.5 \mathrm{~A}$, the material removal rate increase in a convex manner from the smaller electrode diameter to the higher electrode diameter. In case the current is $3.5 \mathrm{~A}$, the wear rate decreases in a concave manner from the smaller electrode diameter to the higher electrode diameter .Fro current setting of $6.5 \mathrm{~A}$, higher wear rate was observed on the electrode diameter of $12 \mathrm{~mm}$, followed 9.5 and $20 \mathrm{~mm}$.

\section{References}

[1] A.K.M.N. Amin, A.K. Sardar, "Investigation of the influence of the properties of the work and tool materials on performance level of electrical discharge machining process", Advanced in Materials Processing Technology, Portugal, 1997, pp. 616-623.

[2] C.C, Marty, "Investigation of surface temperature in electro discharge machining", J. Eng.ind., 1977, 682-684.

[3] V.S.R. Murti, P.K. Philip, An analysis of the debris in ultrasonic assisted electrical discharge machining, Wear 117, 1987, 241-250.

[4] Y.H. Guu, H. Hocheng, C.Y. Chou, C.S. Deng, "Effect of electrical discharge machining on surface characteristics and machining damage of AISI D2 tool steel", Materials science and Engineering, A 358, 2003, pp. 37-43. 